TAO, Vol. 15, No. 1, 97-110, March 2004

NOTES AND CORRESPONDENCE

\title{
Association of Five Moderate-Large Earthquakes to the Faults in Taiwan
}

\author{
Chung-Han Chan $^{1, *}$ and Kuo-Fong $\mathrm{Ma}^{1}$
}

(Manuscript received 17 October 2003, in final form 29 December 2003)

\begin{abstract}
Five moderate-large earthquake sequences were relocated using the double-difference earthquake location algorithm called hypoDD to study their association to the faults in Taiwan. The relocation after hypoDD shows better clusters of aftershock seismicity by using the concept of multiple events. Our results show that the rupture of 1993 Da-Pu earthquake resulted from a northeast-southwestern strike, western dipping fault. Geologically, there is no clear and direct geological feature that is consistent with this feature in this area. Thus, the 1993 Da-Pu earthquake might be attributed to a blind thrust. The rupture of the 1995 Nan-Ao earthquake shows a clear east-west strike, southern dipping fault. It might be related to the Lupihsi fault. The rupture of 1997 Ruey-Li earthquake strike is NESW, eastern dipping. The fault associated with this earthquake was either Tachienshan fault or Chukou fault. The rupture of Chia-Yi earthquake had the strike in N-S, western dipping. No clear geological structure in this region is associated with this feature. We infer that the Chia-Yi mainshock might have also resulted from a blind thrust. The aftershock distribution of the 1999 Chi-Chi earthquake shows clear involvement of nearby active faults. This implies the triggering of nearby active faults after the mainshock. On the Chelungpu fault ruptured plane, most of the aftershocks occurred in the region with less slippage during the mainshock. This suggests the almost total release of the stress along the Chelungpu fault during the rupture. The possible involvement of blind thrust in southwestern Taiwan suggests the importance of understanding the possibility of a blind thrust structure beneath Taiwan.
\end{abstract}

1 Institute of Geophysics, National Central University, Chung-Li, Taiwan, ROC

* Corresponding author address: Prof. Chung-Han Chan, Institute of Geophysics, National Central University, Chung-Li, Taiwan, ROC; E-mail: han@eqkc.earth.ncu.edu.tw 
(Key words: Double-difference earthquake location algorithm, Da-Pu earthquake, Nan-Ao earthquake, Ruey-Li earthquake, Chi-Chi earthquake, and Chia-I earthquake)

\section{INTRODUCTION}

The complex tectonic setting of Taiwan makes Taiwan one of the most seismic active regions in the World. Due to the northwestern collision of Philippine Sea Plate, the distribution of the active faults in Taiwan is with strikes mostly in a north-south direction, with a shallow dipping thrust fault mechanism. Due to this mechanism, the seismicity of Taiwan is rather random in map-view, and it is difficult to understand the direct correlation of the earthquakes to the known active faults. Figure 1 shows the active fault distribution of Taiwan, as

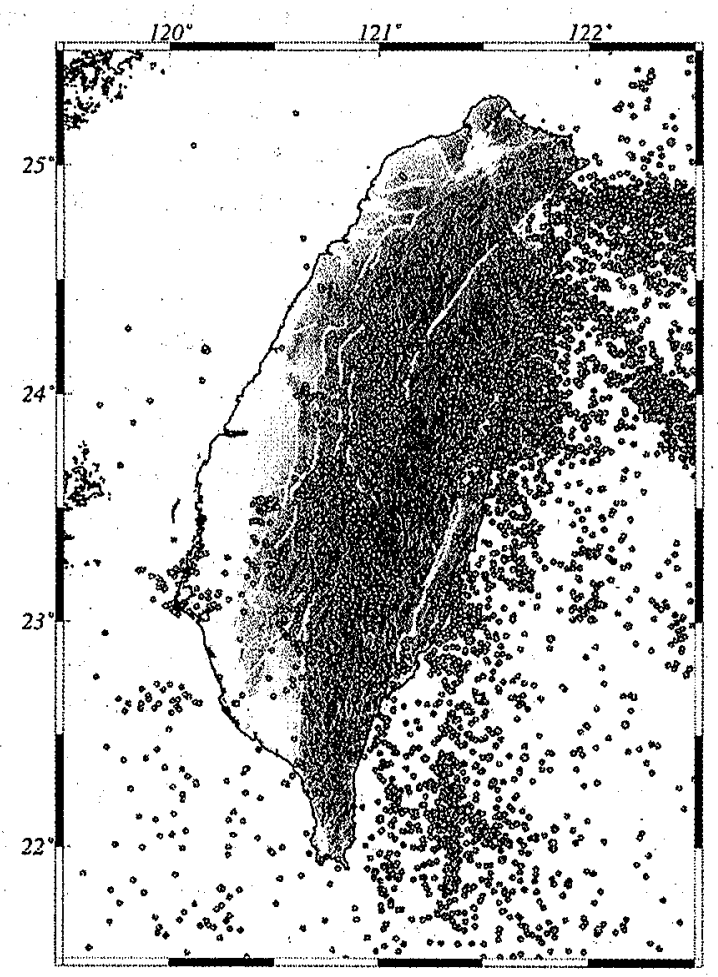

Fig. 1 The active fault distribution of Taiwan (solid lines) investigated by Central Geological Survey of Taiwan with Taiwan topography map and the background seismicity of $M>4$ (circles) since 1976 from Central Weather Bureau Seismogram Network (CWBSN) data. 
investigated by Central Geological Survey of Taiwan and the background seismicity of $M>4$ since 1976. Except for the 1999 Chi-Chi $\mathrm{M}_{\mathrm{w}} 7.6$ earthquake, which ruptured the Chelungpu fault, most of the earthquakes that occurred in Taiwan did not rupture the surface. Thus, the earthquakes' association with known faults remains ambiguous. This fact suggests the possible existence of subterranean blind thrusts.

One of the reasons for the random distribution of the earthquakes is lack of the accuracy in earthquake location identification. Better earthquake location will provide important information about deep tectonic structures. Several efforts (e.g., Mendoza and Hartzell 1988; Got et al. 1994; Waldhauser et al. 1999) have been made to develop different techniques of earthquake relocation in order to have better resolution in earthquake location. Waldhauser and Ellsworth (2000) developed a technique, the so-called double-difference earthquake location algorithm (hypoDD), for relocating earthquakes in Northern California. This technique showed a significant improvement in earthquake locations and clear images of the seismicity to the faults. HypoDD is a method that uses the concept of multiplet to relocate a group of earthquakes at the same time. Multiplet is simply defined as a cluster of nearby multiple events, which were recorded by the same station. Because of the similar hypocenters, the travel time residual from source, path, and site effect can be ignored. The travel time differences among the multiple events are attributed to the differences in their relative locations. Thus, the correlation within the multiple events can be identified. This method is good for the regions with high seismicity and dense seismic network, as Taiwan. Using the better seismic instrumentation available since 1993, we adopted the hypoDD algorithm to relocate the aftershocks of middle-to-large earthquakes in the past ten years in the Taiwan area using data from the Central Weather Bureau Seismogram Network (CWBSN).

\section{DATÁ AND METHOD}

Figure 2 shows the distribution of $M>5.5$ inland Taiwan earthquakes since 1991 . We considered only the events with relatively high aftershock activity. Thus, we allowed for hypoDD aftershock relocation for further possible associated fault identifications. Eventually, five events were selected for the study. They are aftershock sequences of 15 December 1993 Da-pu (M5. 7); 5 June 1994 Nan-Ao (M6.2); 17 July 1998 Ruey-Li (M6.2); 21 September 1999 Chi-Chi (M7.3); and 22 October 1999 Chia-Yi (M6.4) earthquakes. The distribution of the selective events is also shown in Fig. 2. Table 1 shows the origin time, location and magnitude of the selective events provided by Central Weather Bureau Seismological Network (CWBSN). In the study, we considered all the possible determined focal mechanisms of the events, as identifiable from first motions or waveform moment tensor inversion from BATS or IRIS.

The accuracy of hypocenter location is affected by several factors, including knowledge of the velocity structures (Pavlis 1986; Gomberg et al. 1990), available phases, arrival time reading accuracy, and the network geometry. The double-difference earthquake location algorithm employed in this study is based on the concept of multiplets (a group of earthquakes which are close to each other). The multiplet earthquakes have similarities in location as well as in focal mechanism. The station records the waveforms of the mutiplets with a similar ray 


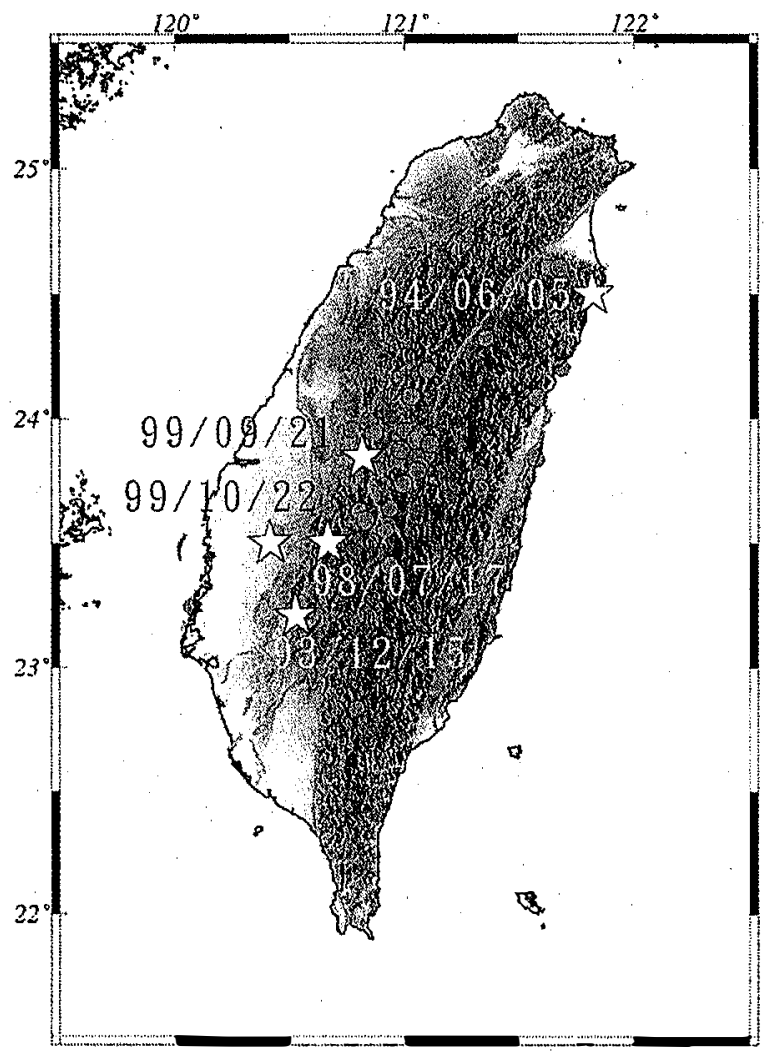

Fig. 2 Distribution of $M>5.5$ inland Taiwan earthquakes since 1991.

path; thus, the effects of velocity structure can be ignored. The travel time difference among the earthquakes in the multiplets is attributed to the difference in the locations relative to each other.

To minimize error in earthquake relocation, the parameters (MINWGHT, MAXDIST and MAXSEP) used in hypoDD were tested for each earthquake sequence, to assure the accuracy of results. These parameters are important for the quality of data and definition of multiples. MINWGHT represents the minimum weighting used in the relocations, It corresponds to the quality of data. The definition from CWBSN on quality of earthquake location, named from $0-4$, is transferred to the amount of weighting. MAXDIST represents the maximum distance of the station to the defined multiplet. MAXSEP defines the maximum separation of the events within the multiplet. After several testings, the parameters for the five selective events are 
Table 1. * According to the CWB quality parameter from 0 to 4 , the weighting values are given $1,0.5,0.25$, and 0.0625 , respectively.

\begin{tabular}{|c|c|c|c|c|c|c|}
\hline \multicolumn{2}{|c|}{ Earthquake } & $\mathrm{Da}-\mathrm{Pu}$ & Nan-Ao & Ruey-Li & Chi-Chi & Chia-Yi \\
\hline \multirow{6}{*}{ Origin Time } & year & 1993 & 1994 & 1998 & 1999 & 1999 \\
\hline & month & 12 & 6 & 7 & 9 & 10 \\
\hline & day & 15 & 5 & 17 & 20 & 22 \\
\hline & hour & 21 & 1 & 4 & 17 & 2 \\
\hline & minute & 49 & 9 & 51 & 47 & 18 \\
\hline & second & 43.1 & 30.09 & 14.96 & 15.85 & 556.8 \\
\hline \multirow{3}{*}{ Location } & Longitude $\left({ }^{\circ}\right)$ & 120.523 & 121.838 & 120.663 & 120.815 & 120.422 \\
\hline & Latitude $\left(^{\circ}\right)$ & 23.213 & 24.462 & 23.503 & 23.852 & 23.517 \\
\hline & depth $(\mathrm{km})$ & 15.21 & 5.13 & 6 & 8 & 16.59 \\
\hline \multicolumn{2}{|c|}{ Magnitude } & 5.7 & 6.2 & 6.2 & 7.3 & 6.4 \\
\hline \multicolumn{2}{|c|}{ MINWGHT $^{*}$} & 0 & 0.0625 & 0 & 0 & 0 \\
\hline \multicolumn{2}{|c|}{ MAXDIST (km) } & 80 & 90 & 40 & 100 & 50 \\
\hline \multicolumn{2}{|c|}{$\operatorname{MAXSEP}(\mathrm{km})$} & 3.5 & 3.5 & 4 & 10 & 5 \\
\hline
\end{tabular}


determined and shown in Table 1. Previous studies on the hypoDD relocations (Waldhauser and Ellsworth 2000) had shown the significant advantage of hypoDD relocation in identifying the possible associated seismic structure. Thus, in this study, the comparison before and after relocation was not addressed. We concentrated our study on the association of the earthquake to the possible geological faults after hypoDD relocation.

\section{RESULTS AND DISCSSIONS}

\section{Da-Pu Earthquake (15 December 1993, $M=5.7$ )}

The Da-Pu earthquake was relocated by Wu et al. (1998) at longitude $120.507^{\circ} \mathrm{E}$, and latitude $23.194^{\circ} \mathrm{N}$, with a depth of $15.21 \mathrm{~km}$. The focal mechanism determined by Shin (1998) shows thrust faulting mechanism with strike $=200^{\circ}$, dip $=48^{\circ} \mathrm{W}$, and rake $=84^{\circ}$. Figure 3a shows one-month aftershock seismicity in the Da-Pu region after hypoDD relocation. Due to the thrust faulting mechanism, the pattern of the fault structure is difficult to determine from the aftershock distribution spatially. The sesimicity profiles perpendicular to the two focal planes were made and shown in Figs. 3b, c, respectively. They both show a clear western dipping structure at depths of 15 to $25 \mathrm{~km}$, with a dip angle of about 45 degrees.

The geology in this area is mainly controlled by near-parallel thrust faults and folding, acting to form a series of NE-SW strike faults (Fig. 3d) where the Shianzhiaushan fault is a strike slip fault and the Chishan, Pinghsi and Chutouchi faults are eastern dipping thrust faults (Fig. 3e). None of these identified geological faults is consistent with the identified ruptured pattern of the Da-Pu earthquake sequence. Thus, the occurrence of the Da-Pu earthquake might be related to a blind thrust fault in southwestern Taiwan.

\section{Nan-Ao Earthquake (5 June 1994, M = 6.2)}

The Nan-Ao earthquake occurred at $121.787^{\circ} \mathrm{E}, 24.468^{\circ} \mathrm{N}$ and $5.13 \mathrm{~km}$ in depth (Wu et al. 1998). The focal mechanism is a strike-slip fault mechanism with strike $=87^{\circ}$, dip $=81^{\circ} \mathrm{S}$, and rake $=8^{\circ}$. Due to high aftershock activity, only one-day aftershocks were used for hypoDD relocation. Fig. 4a shows the one-day aftershock distribution. It shows an apparent EW distribution pattern in the map-view that would be consistent with a determined strike slip focal mechanism. The profile perpendicular to the east-west focal plane (Fig. 4b) shows a near vertical dipping rupture plane at depths of 5 to $20 \mathrm{~km}$.

Geologically, the Nan-Ao earthquake is located on the Ilan plain. Tectonically, it is related to the opening of Okinawa trough. Two geological faults, the Lupishi and the Nanao, were identified near the Nan-Ao earthquake (Fig. 4c). They both show E-W strike, with near vertical southern dipping plane (Fig. 4d). According to the focal depth of $5 \mathrm{~km}$, the possible associated fault for the Nan-Ao event could be the Lupishi fault. However, neither the Lupishi nor the Nanao fault was identified as an active fault geologically. The association of this earthquake to the Lupishi fault might imply the activity of the fault beneath the surface, which has been undetected at the surface. 
(a)

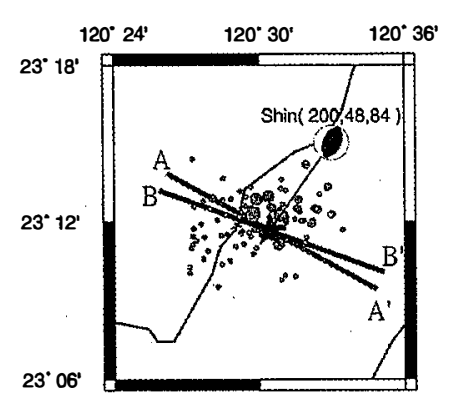

(b)

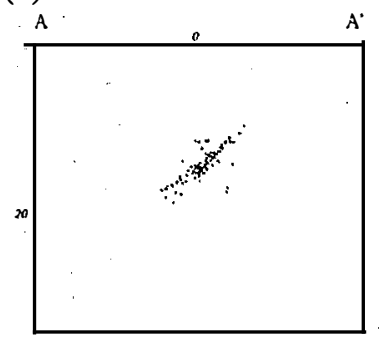

(c)

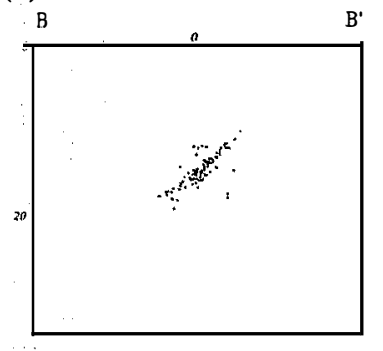

(in $\mathrm{km}$ ) (d)

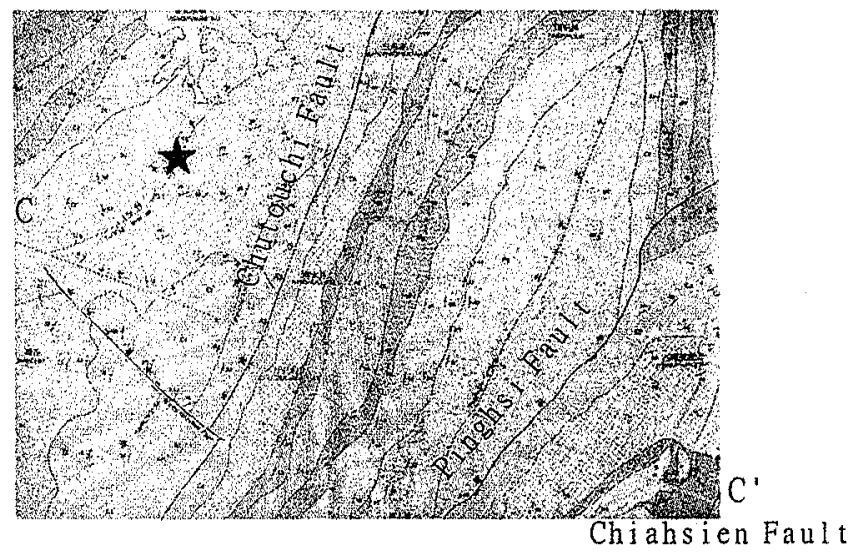

(e)

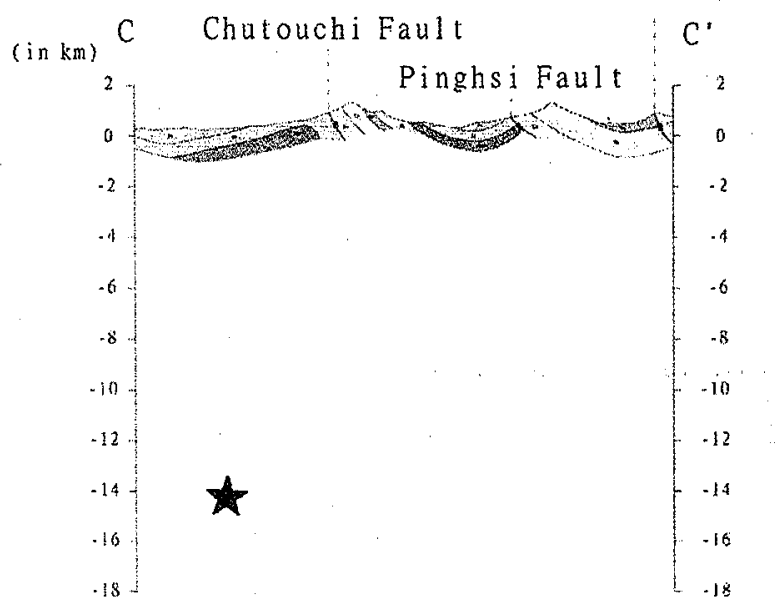

Fig. 3. The map-view (a) and cross-sections perpendicular to two focal planes, $\mathrm{AA}^{\prime}$ (b), and BB'(c) of the Da-Pu mainshock(star) and aftershocks(circles) compared with the geological structures around Da-Pu area, which are map-view(d) and cross-section(e) from geological map of Taiwan Chiahsien, published by Central Geological Survey. The hypocenters of Da-Pu aftershocks are plotted on the cross-section of geological structure. No fault fits the pattern of aftershock, so that we infer the Da-Pu earthquake might be attributed from a blind thrust. 
(a)

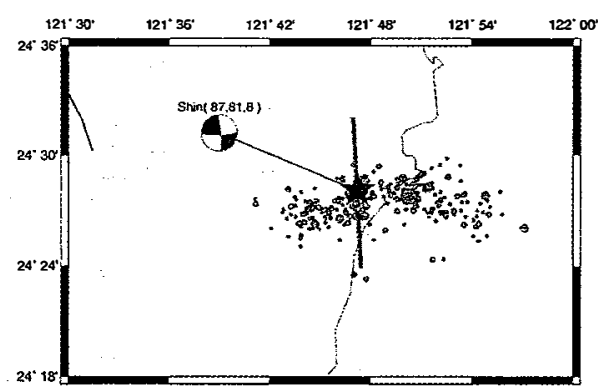

(b)

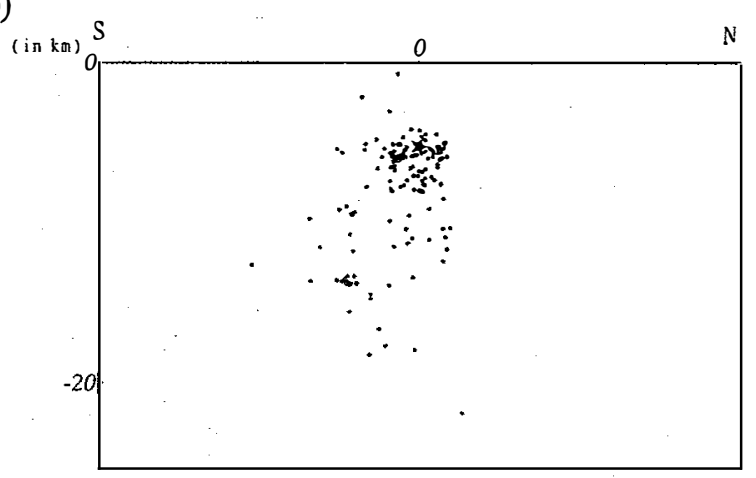

(c)

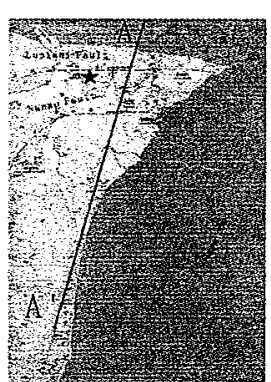

(d)

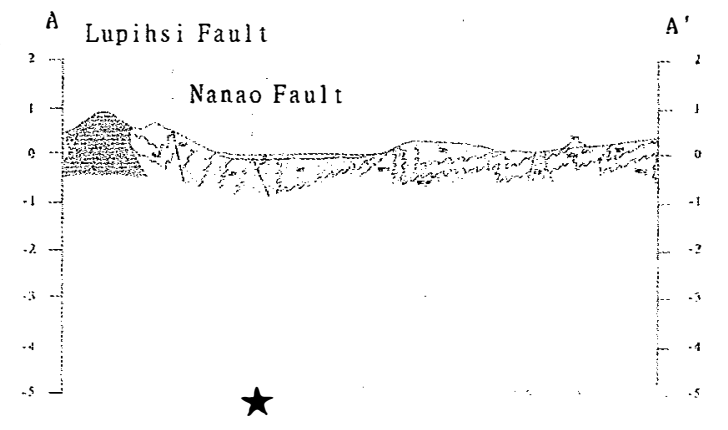

Fig. 4. The map-view(a) and cross-section perpendicular to the focal plane(b) of the Nan-Ao aftershocks and compared with the geological structure around the Nan-Ao earthquake, which are map-view(c) and crosssection(d), from geological map of Taiwan - Nanao, published by Central Geological Survey. 


\section{The Ruey-Li Earthquake (17 July 1998, $M=6.2$ )}

The Ruey-Li earthquake occurred at $120.66^{\circ} \mathrm{E}, 23.50^{\circ} \mathrm{N}$ and $6.00 \mathrm{~km}$ in depth, according to relocation by Wu et al. (1998). The focal mechanism from the first motions of P-wave, as identified by Chang (1998), is a thrust fault with strike $=45^{\circ}$, dip $=50^{\circ} \mathrm{SE}$, and rake $=110^{\circ}$. One-month aftershocks after relocation are shown in Fig. 5a. Perpendicular to the two focal planes shown in Figs. 5b, c, respectively, the profiles show clear southeastern dipping plane at depths of near the surface to $15 \mathrm{~km}$.

The geological structure near the Ruey-Li earthquake is shown in Figs. 5d, e, respectively. The geological faults in this area are NW-SE left-lateral strike direction of the Shuisheliao fault; and NE-SW strike thrust the Luku, Tachienshan, and Chukou faults. According to the aftershock patterns and focal depth, the possible associated fault to the Ruey-Li earthquake is either the Tachienshan fault or the Chukou fault.

\section{The Chi-Chi Earthquake (21 September 1999, $M=7.3$ )}

The Chi-Chi earthquake's association to the fault is obvious, due to the clear surface rupture of the Chelungpu fault, which ruptured about $100 \mathrm{~km}$ in length. The Chi-Chi earthquake occurred at $120.75^{\circ} \mathrm{E}, 23.87^{\circ} \mathrm{N}$, and $7.00 \mathrm{~km}$ in depth. The aftershock distribution associated with the Chi-Chi earthquake was very broad, and has been discussed (e.g., Chang et al. 2000; Kao and Chen 2000).

They relocated the six-month aftershocks of the Chi-Chi earthquake using HypoDD, as shown in Fig. 6a. Most of aftershocks were distributed in the Central Range. Few of the aftershocks occurred near the Chelungpu fault itself. The profile perpendicular to the strike of the Chelungpu fault (Fig. 6b) shows most of the aftershocks located compatibly with near-by faults, as the Shangtung, and Shuikeng faults. This suggests that the near-by active faults might be riggered. A clear sesimicity lineation is also observed near the bottom of the Changhua fault. Figure $6 \mathrm{c}$ shows the aftershock distribution along the ruptured Chelungpu fault plane (Strike $=3^{\circ}$ and dip $\left.=30^{\circ}\right)$. The projections of these aftershocks are the events located within $5 \mathrm{~km}$ of the fault plane in depth. Compared with the spatial slip distribution determined by $\mathrm{Ma}$ et al. (2001), most of the aftershocks located in the region had less slippage during the mainshock. The Coulomb stress change calculation associated with the mainshock (Ma et al. 2002) shows that the aftershocks were located in regions where stress increased after the Chi-Chi earthquake. The stress near the surface of the fault was completely released (Andrew et al. 2001; Ma et al. 2003). The total release of the stress near the Chelungpu fault left less stress available for aftershocks. This feature has been observed in several large earthquakes studied by Mendoza and Hartzell (1988).

\section{Chia-Yi Earthquake (22 October 1999, $M=6.4$ )}

The Chia-Yi earthquake occurred at $120.426^{\circ} \mathrm{E}, 23.515^{\circ} \mathrm{N}$, and at the depth of $16.64 \mathrm{~km}$. The focal mechanism determined from Harvard CMT shows the strike $=346^{\circ}$, and dip $=33^{\circ}$ (Fig. 7a). The profile perpendicular to the strike of the fault is shown in Fig. 7b. 
(a)

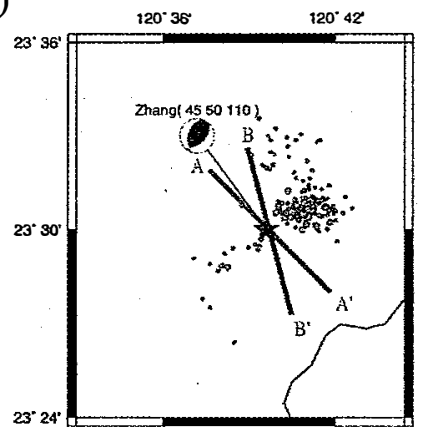

(b)

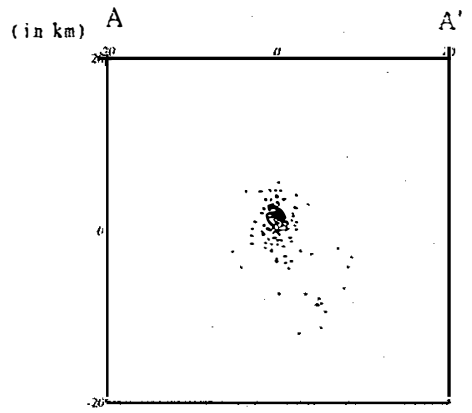

(d)

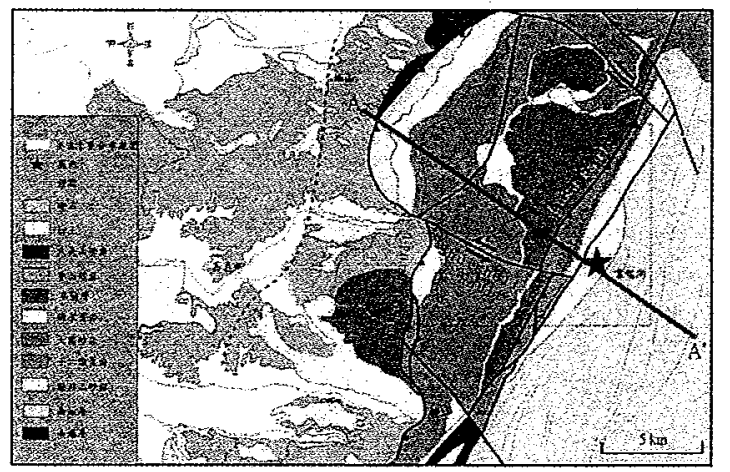

(e)

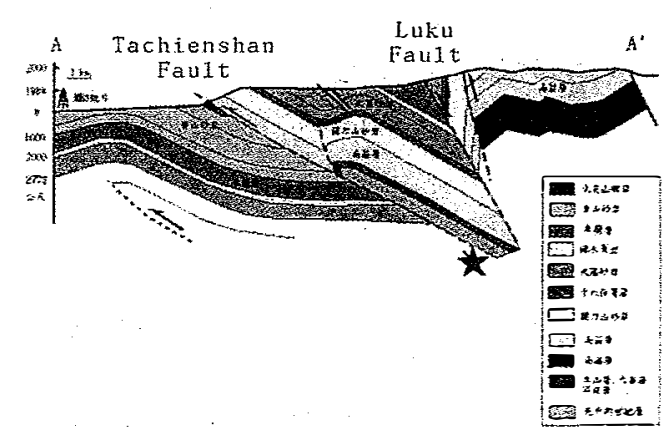

Fig. 5. The map-view(a) and cross-sections perpendicular to two focal planes(b)(c) of the Ruey-Li aftershocks and compared with the geological structure around this area, which are map-view(d) and cross-section(e) from Central Geological Survey. According to the direction of strike and dipping angle, the association of the fault to this earthquake was to either the Tachienshan or the Chukou fault 
(a)

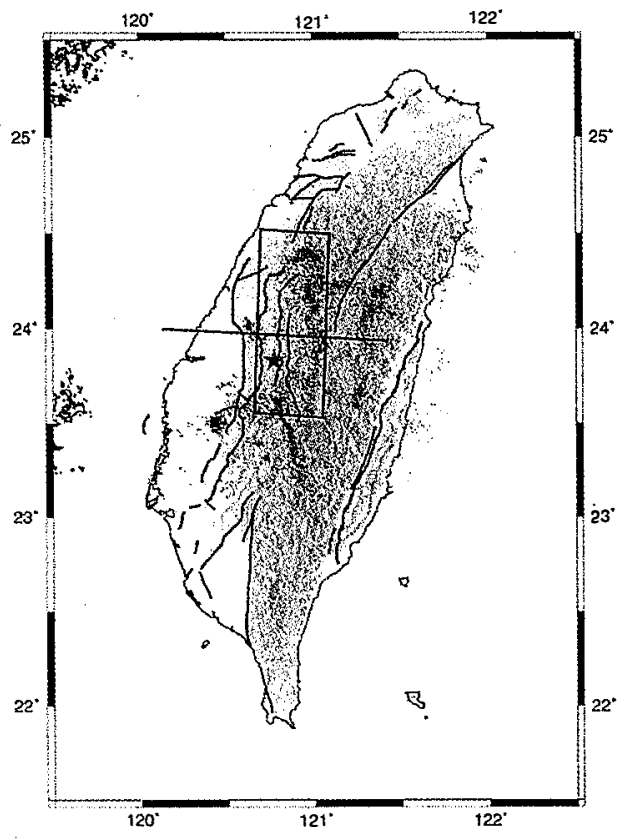

(b)

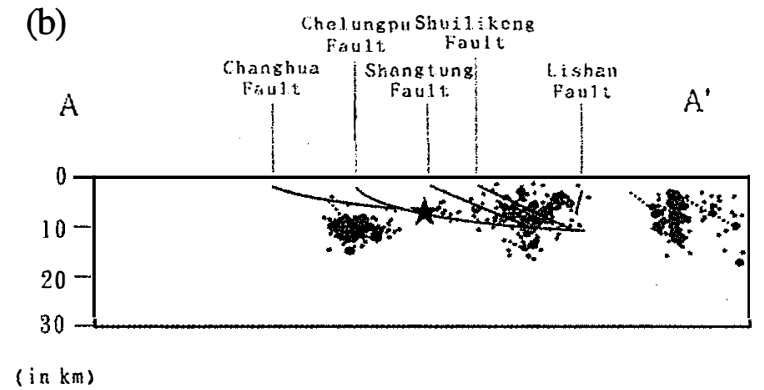

(c)

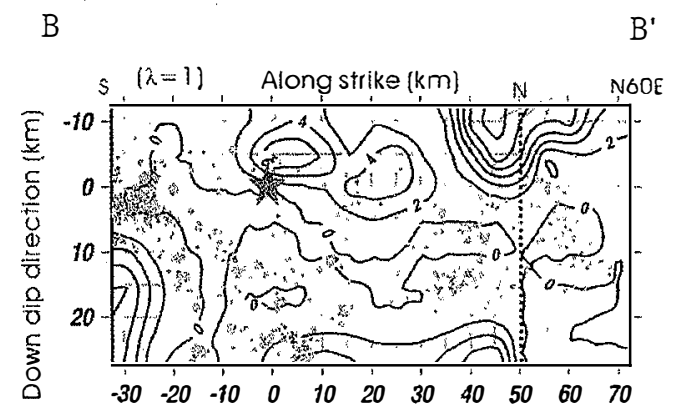

Fig.6. The relocated six-month aftershocks of the Chi-Chi earthquake after relocation(a). Most of aftershocks were distributed in the Central Range. Fewer aftershocks occurred near the Chelungpu fault. The profile perpendicular to the strike of the Chelungpu fault(b) shows most of the aftershocks located compatibly with near-by faults, such as the Shangtung and the Shuikeng faults determined by Chu et al. (2001). This suggests that the near-by active faults might be triggered. A clear sesimicity lineation is also observed near the bottom of the Changhua fault. Figure $6 \mathrm{c}$ shows the aftershock distribution along the ruptured Chelungpu fault plane $\left(\right.$ Strike $=3^{\circ}$ Dip $\left.=30^{\circ}\right)$.

The geological faults in this region are the Meishan, Chiuhsiungken and TachienshanChukou faults (Fig. 7c). The first one is a strike-slip fault, while the latter two are eastern dipping thrust faults. None of these identified active faults shows a pattern consistent with the observed western ruptured fault plane. Thus, the 1999 Chia-Yi earthquake might be attributed to another blind thrust in the southwestern plain. The association of the 1999 Chia-Yi earthquake to the 1999 Chi-Chi earthquake has been debated. The ruptured plane of the Chia-Yi earthquake shows a different pattern than does the Chi-Chi earthquake. It might have been 
(a)

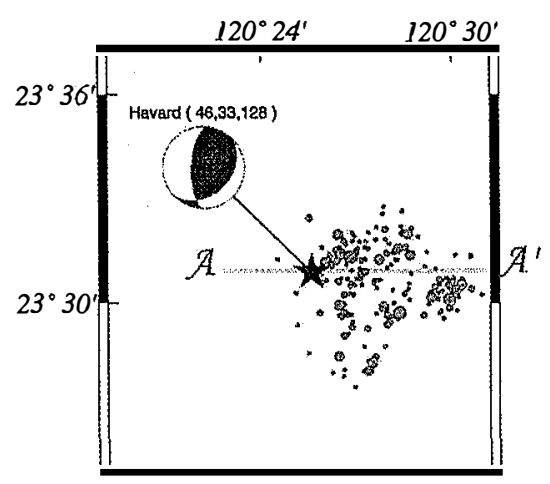

(b)

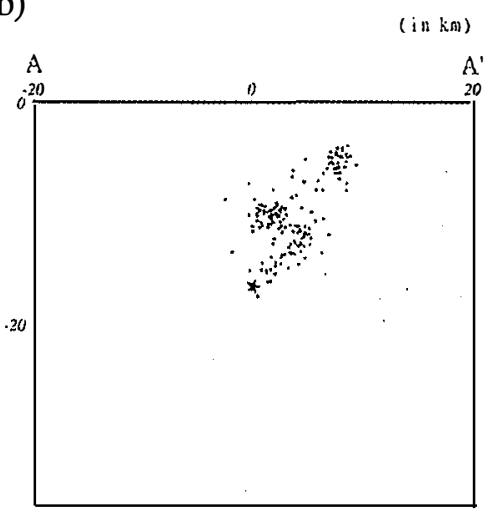

(c)

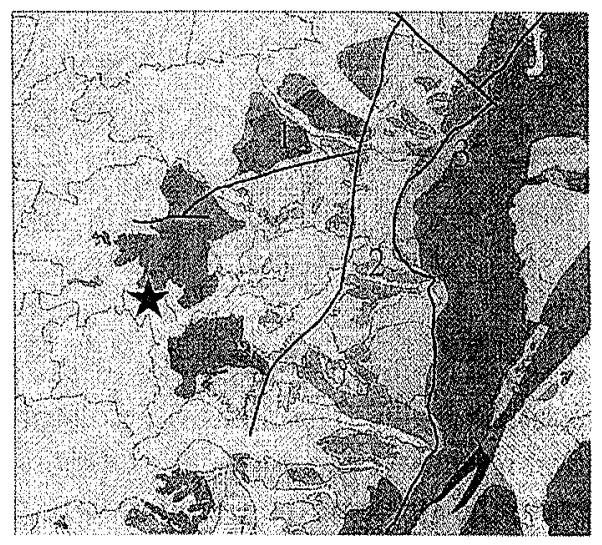

Fig.7 The map-view(a) and cross-sections perpendicular to focal plane, as determined by Harvard CMT(b), and compared with the geological structure near the Chia-Yi mainshock(c), which 1. Meishan fault, 2. Chiuhsiungken fault, 3. Tachienshan-Chukou fault, as determined from the Chinese Petroleum Corporation geological map.

induced by the blind thrust triggered by the 1999 Chi-Chi earthquake.

Southwestern Taiwan had been a highly seismic, hazardous region. Historically, numerous large earthquakes have occurred in this region, including the 1792 M7.1 and 1906 MeiShan earthquakes (Tsai 1985). The possible involvement of the large earthquakes associated with blind thrusts illustrates the importance of the understanding of the underground fault structures. 


\section{CONCLUSIONS}

Five moderate-large earthquake sequences were relocated using the hypoDD to study their association to the faults in Taiwan. The technique of relocation from hypoDD shows better clusters of aftershock seismicity by using the concept of multiple events. Our results show that the rupture of $1993 \mathrm{Da}$-Pu earthquake resulted from a northeast-southwestern strike, western dipping fault. Geologically, there is no clear and direct geological feature consistent with this feature in this area. Thus, the $1993 \mathrm{Da}-\mathrm{Pu}$ earthquake might be attributed to a blind thrust. The rupture of the 1995 Nan-Ao earthquake shows clear east-west strike with southern dipping fault. It might be related to the Lupihsi fault. The rupture of 1997 Ruey-Li earthquake shows a strike in NE-SW, with eastern dipping. The fault associated to this earthquake was either the Tachienshan or the Chukou fault. The rupture of Chia-Yi earthquake had the strike in N-S, with western dipping. No clear geological structure in this region can be associated with this feature. According to the geological structure of this area, we infer that there is a blind zone cause the Chia-Yi mainshock. The occurrence of this earthquake might be also attributed to a blind thrust. The aftershock distribution of the 1999 Chi-Chi earthquake shows the involvement of near-by active faults. This implies the triggering of the near-by active faults after the mainshock. On the Chelungpu fault ruptured plane, most of the aftershocks occurred in the region with less slippage during the mainshock. This suggests the almost total release of stress along the Chelungpu fault during the rupture.

\section{REFERENCES}

Chan, C. H., Y. M. Wu, T. C. Shin, and C. W. Wang, 2000: Relocation of the 1999 Chi-Chi earthquake in Taiwan. TAO, 11, 581-590.

Chang, C. S., T. C., Shin, and C. Y. Wang, 1998: 1998 Ruey-Li earthquake - the slip at portion of thrust structure. $7^{\text {th }}$ Annual Taiwan Area Geophysical meeting, 1-12. (in Chinese)

Gomberg, J. S., K. M. Shedlock, and S. W. Roecker, 1990: The effect of S-wave arrival times on the accuracy of hypocenter estimation. Bull. Seismol. Soc. Am., 80, 1605-1628.

Got, J. L., M. J. Fréchet, and F. Klein, 1994: Deep fault plane geometry inferred from multiplet relative relocation beneath the south flank of Kilauea, J. Geophys. Res., 99, 1537515386.

Kao, H., and W. P. Chen, 2000: The Chi-Chi earthquake sequence; active, out-of-sequence thrust faulting in Taiwan. Science, 288, 2346-2349.

Ma, K. F., J. Mori, S. J. Lee, and S. B. Yu, 2001: Data file from Spatial and Temporal Distribution of Slip for the 1999 Chi-Chi, Taiwan Earthquake. Bull. Seis. Soc. Am., 91, 13811382.

Ma, K. F., E. E. Brodsky, J. Mori, C. Ji, T. R. A. Song and H. Kanamori, 2003: Evidence for Fault Lubrication during the 1999 Chi-Chi, Taiwan, Earthquake (Mw7.6). Geophys. Res. Lett., 30, 1244.

Ma, K. F. and T. R. A. Song, 2003: Thermomechanical structure beneath young orogenic belt 
of Taiwan, Tectonophysics, (in press).

Mendoza, C.,and S. H. Hartzall, 1988: Aftershock patterns and main shock faulting. Bull. Seism. Soc. Am., 78, 1438-1449.

Pavlis, G. L., 1986: Appraising earthquake hypocenter location errors: acomplete, practical approach for single-event locations. Bull. Seismol. Soc. Am., 76, 1699-1717.

Tsai, Y. B., 1985: A study of disastrous earthquakes in Taiwan, 1683-1895. Bull. Inst. Earth Sci. Academia Sinica, 5, 1-44.

Waldhauser, F., W. L. Ellsworth, and A. Cole, 1999: Slip-parallel seismic lineations along the northern Hayward fault, California, Geophys. Res. Lett., 26, 3525-3528.

Waldhauser, F., and W. L. Ellsworth, 2000: A Double-difference earthquake location Algorithm: method and application to the northern Hayward fault. California, Bull. Seism. Soc. Am., 90, 1353-1368.

Wu, Y. M., C. S. Chang, and T. C. Shin, 1998: Analyzing 1998 Ruey-Li, Chia-Yi earthquake and the introspection of real-time earthquake reporting. $7^{\text {th }}$ Annual Taiwan Area Geophysical meeting, 33-46. (in Chinese) 